\title{
Immunohistological characterisation of retinoblastoma and related ocular tissue
}

John F Tarlton, David L Easty

\begin{abstract}
The immunohistological reactivity of six retinoblastomas was investigated by means of 18 monoclonal antibodies and compared with that of adult and fetal retina. The antigenic profiles were found to be characteristic for each cell type studied and indicated that a panel of monoclonal antibodies could achieve a specific immunolocalisation not afforded by any single antibody. Immunohistological comparison between retinoblastoma and adult and fetal retinal cells provided evidence of the histogenesis of the tumour. The data suggest that the tumour arises from an early multipotential cell, which retains the capacity to develop differentiation characteristics associated with inner or outer retinal cell types, resulting in a heterogeneous tumour cell population. A cell with such differentiation potential predominates in the retina prior to the primitive neuroepithelial layer division at eight weeks' gestation.
\end{abstract}

Retinoblastoma is the commonest ocular malignancy of newborn babies and infants. Despite advances in early diagnosis and treatment, the mortality rate due to metastatic spread remains above $15 \%$. It is particularly high in parts of the world where there is a lack of immediate medical care. Although established therapeutic techniques are effective in dealing with most primary malignancies, it is the metastases that kill, ${ }^{1}$ and further techniques must be investigated for their identification and treatment.

The clinical applications of monoclonal antibodies have been explored with regard to the diagnosis and treatment of neuroectodermally derived tumours. ${ }^{1-11}$ A panel of monoclonal antibodies, tailored to the antigenic profile of the tumour, may be used to locate malignant cells in extraocular sites such as cerebrospinal fluid ${ }^{1012}$ and bone marrow, ${ }^{81314}$ and help to determine the extent of metastatic spread. In addition tumourpositive antibodies have potential value in immunotherapy and drug targeting to prevent the dissemination of tumour cells. Knowledge of the immunohistochemical reactivity of the tumour would also provide a useful adjunct to conventional histological classification and assist in assessing the prognosis.

In order to explore these and other potential uses of monoclonal antibodies comprehensive data on the immunochemical reactivity of the tumour are required, and antibodies must be assessed to determine their relative affinity for retinoblastoma and normal ocular tissue.

The histogenesis of retinoblastoma has been the subject of many recent investigations. Histological and microscopic studies have demon- strated characteristics associated with both astrocytic and photoreceptor cells, ${ }^{1516}$ and immunohistological investigations using antibodies against antigens associated with specific cell types, such as glial fibrillary acidic protein, ${ }^{15} 17-22 \mathrm{~S}-100,{ }^{20}$ retinal s-antigen, ${ }^{152324}$ and neuron specific enolase,,$^{15} 17202125$ have indicated both neuronal and glial origin of retinoblastoma. Since such evidence remains inconclusive, an alternative approach to elucidate further the origin of the tumour is to compare its antigen expression with that of adult and fetal retinal cell types by means of a panel of monoclonal antibodies recognising a wide range of antigenic determinants. The retinoblastoma stem cell could then be classified according to the developmental lineage of retinal cells.

We report here an immunohistological study of six specimens of retinoblastoma using a panel of 18 monoclonal antibodies directed against antigens associated with neuroe todermal and epithelial tissue, as well as differentiation, oncofetal, and other antigens of mixed phenotypic distribution. Comparisons have been made with the reactions of fetal retinas of various ages and adult retina to provide evidence of the tumour origin.

\section{Materials and methods}

\section{IMMUNOHISTOCHEMISTRY}

Fresh operative samples of six well differentiated retinoblastomas, nine disease-free adult eyes, and 10 fetal eyes, ranging from 10 to 16 weeks' gestation, were snap frozen and stored in liquid nitrogen. Cryostat sections $5 \mu \mathrm{m}$ thick were mounted on gelatin coated slides and air dried for 2 to 24 hours. Endogenous peroxidase activity was blocked by immersion in $2 \%$ hydrogen peroxide for 15 minutes, followed by two 5 minute phosphate buffered saline (PBS) washes, and the sections incubated for 15 minutes with $20 \%$ normal rabbit serum (Nordic) in PBS to block non-specific protein binding sites. Each subsequent incubation was followed by two 5minute PBS washes. $50 \mu \mathrm{l}$ of appropriate monoclonal antibody was added to each section for 60 minutes at room temperature in a humid chamber, followed by successive 15-minute incubations in secondary rabbit antimouse immunoglobulin (Dako, 1:20 in PBS) and tertiary mouse peroxidase antiperoxidase complex (Dako, 1:40 in PBS). The secondary and tertiary stages were repeated to amplify the binding. The sections were soaked in tris buffered saline (TBS, pH 7.6) for 5 minutes, and incubated with 4-chloro-1-naphthol $(10 \mathrm{mg}$ in $100 \mu \mathrm{l}$ ethanol, added to $25 \mathrm{ml}$ TBS containing 
TABLE I Monoclonal antibody panel

\begin{tabular}{|c|c|c|}
\hline$M A b$ & Immunogen & Antigen tissue distribution \\
\hline $\begin{array}{l}\text { RT97 } \\
\text { UJ181.4 } \\
\text { UJ127.11 } \\
\text { BF10 } \\
\text { A Thy-1 } \\
\text { FD32? }\end{array}$ & $\begin{array}{l}\text { Rat brain } \\
\text { 16-Week human fetal brain } \\
\text { 16-Week human fetal brain } \\
\text { Rat brain } \\
\text { Human Thy-1 antigen }\end{array}$ & $\begin{array}{l}\text { 210K subunit neurofilament, neurones } \\
\text { Fetal brain, neuroblastic tumours, PNT } \\
220-240 \mathrm{~K} \text { glycoprotein, brain, neuroblastic tumours } \\
\text { 155K neurofilament, neurones } \\
\text { 20K glycoprotein, neuroblastoma, glioma } \\
\text { 31-34 }\end{array}$ \\
\hline FD44 & $\begin{array}{l}\text { Human glioma } \\
\text { Glioma tissue }\end{array}$ & Blood vesselst \\
\hline P1153/3 & IMR6 NBL cell line & Neural type cells, neuroblastoma" ${ }^{1335}$ \\
\hline $\begin{array}{l}\text { UJ13A } \\
\text { A2B5 }\end{array}$ & 16-Week human fetal brain & All neuroectodermal tissues and tumours ${ }^{3}$ \\
\hline $\begin{array}{l}\text { ALBS } \\
\mathrm{H} 11\end{array}$ & $\begin{array}{l}\text { Chick retunal cell culture } \\
\text { Muscle myoblast }\end{array}$ & $\begin{array}{l}\text { Ganghiocide } G Q \text {, neuroectodermal tissue } \\
\text { Neuroectodermal tissue and tumours }\end{array}$ \\
\hline FD19 & Astrocytoma & GFAP $50 \mathrm{~K}$, glial tissue and tumours ${ }^{6.9}$ \\
\hline M148 & Medulloblastoma & $110-130 \mathrm{Kd}$ membrane glycoprotein, blood platelets \\
\hline LE61 & Cytoskel. ext. epith. cells & $45 \mathrm{~K}$ cytokeratin, simple epithelium, carcinomas ${ }^{34}$ \\
\hline $\begin{array}{l}2.3 F 9 \\
M I / N 1\end{array}$ & $\begin{array}{l}\text { Fibronectin } \\
\text { CHP100 NBL cell line }\end{array}$ & Some neural cells, granulocytes, neuroblastoma ${ }^{\text {to }}$ \\
\hline UJ167.11 & Fetal brain & Some neuroectoderm ${ }^{14}$ \\
\hline UJ308 & Fetal brain & Some neural cells, granulocytes \\
\hline
\end{tabular}

$50 \mu 16 \%$ hydrogen peroxide, and left to allow precipitate to settle) for 30 minutes, giving a black reaction product where antibody binding has occurred. The sections were counterstained with eosin or alcian yellow, and mounted beneath coverslips in Aquamount aqueous mountant (Emscope).

The adult retina samples were stained with the panel of antibodies to establish the consistency of reactions, and thenceforth were placed on the same slide as the tumour and fetal tissue and stained simultaneously in subsequent assays, thereby standardising the results. The intensity and distribution of the staining was

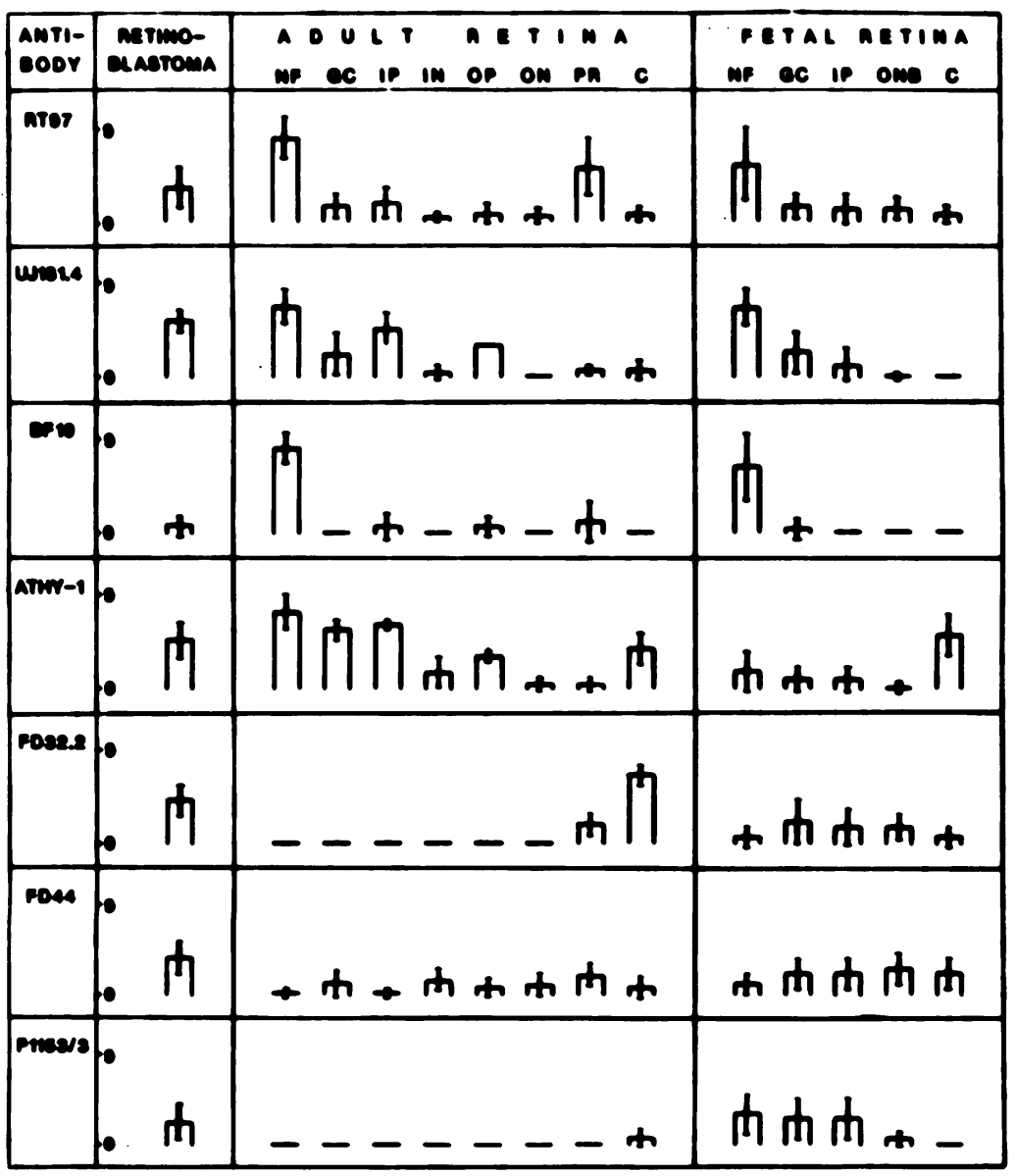

Figure 1: Mean comparative staining intensities of reactions, scored 0 (negative) to 9 (intensely positive), for those antibodies demonstrating variation in tissue affinities. Mean values and standard deviations are shown. $N F$, nerve fibre layer; $G C$, ganglion cell layer; $I P$, inner plexiform layer; IN, inner nuclear layer; $O P$, outer plexiform layer; $O N$, outer nuclear layer; $P R$, photoreceptor layer; $C$ choroid; ONB, outer neuroblastic layer. assessed microscopically, and a score between 0 (negative) and 9 (intense positive) attributed by comparison with the adult retinal tissue. The reactions were repeated a number of times to ensure consistency, and mean values were obtained. In each case adult and fetal ocular tissue acted as positive and negative controls; normal serum and antibody found to be consistently negative provided additional controls.

\section{MONOCLONAL ANTIBODIES}

A panel of 18 monoclonal antibodies was selected for use in the study. These were raised by conventional hybridoma techniques ${ }^{2627}$ and are listed in Table $I$, along with their antigen tissue distribution where known, and reference to their origin.

\section{Results}

A total of 29 examinations were conducted on the retinoblastoma samples and 22 on both the adult and fetal retinas, by means of the panel of monoclonal antibodies.

Each tumour sample displayed marked heterogeneity in its binding of some of the monoclonal antibodies (particularly ATHY-1, FD32.2, and FD44). In these cases the overall staining intensity was recorded:

Monoclonal antibodies UJ13A, A2B5, and $\mathrm{H} 11$ were strongly positive in all retinal tissues and retinoblastoma; M148 and FD19 were moderately positive in all tissues; and UJ127.11 showed identical distribution to UJ181.4. Antibodies found to be negative throughout were LE61, 2.3F9, UJ167.11, UJ308, and the MI/ $\mathrm{N} 1$. The comparative antigen expressions for the other antibodies in the panel are shown in Figures 1 and 2, and examples of the immunohistological reactions are illustrated in Figures 3 and 4.

\section{ANTIBODY LOCALISATION}

The reactions of antibodies which differentially marked the tissues assessed in this study, namely RT97, UJ181.4 (UJ127.11), BF10, A THY1, FD32.2, FD44, and P1153/3, are illustrated in Figure 1, and those of antibodies which showed variable affinities for fetal retinas of different ages are shown in Figure 2.

RT97 (neurofilament antigen). This cytoplasmic antigen was expressed in the nerve fibre layer after 12 weeks' gestation, and in mature photoreceptors. Retinoblastoma showed mild affinity for this antibody, though this was particularly sensitive to antibody titre.

UF181.4, UF127.11 (neuroblastic antigens). In all tissues characterised it was found that these cell surface antigens were expressed in parallel, remaining constant throughout development, and limited primarily to the inner retinal layers. Moderate to intense expression was seen in all the retinoblastomas.

BF10 (neurofilament antigen). This cytoplasmic antigen was limited in distribution to the nerve fibre layer of post 11-week retina.

A THY-1 (human Thy-1 antigen). There was found to be moderate to intense marking of the 


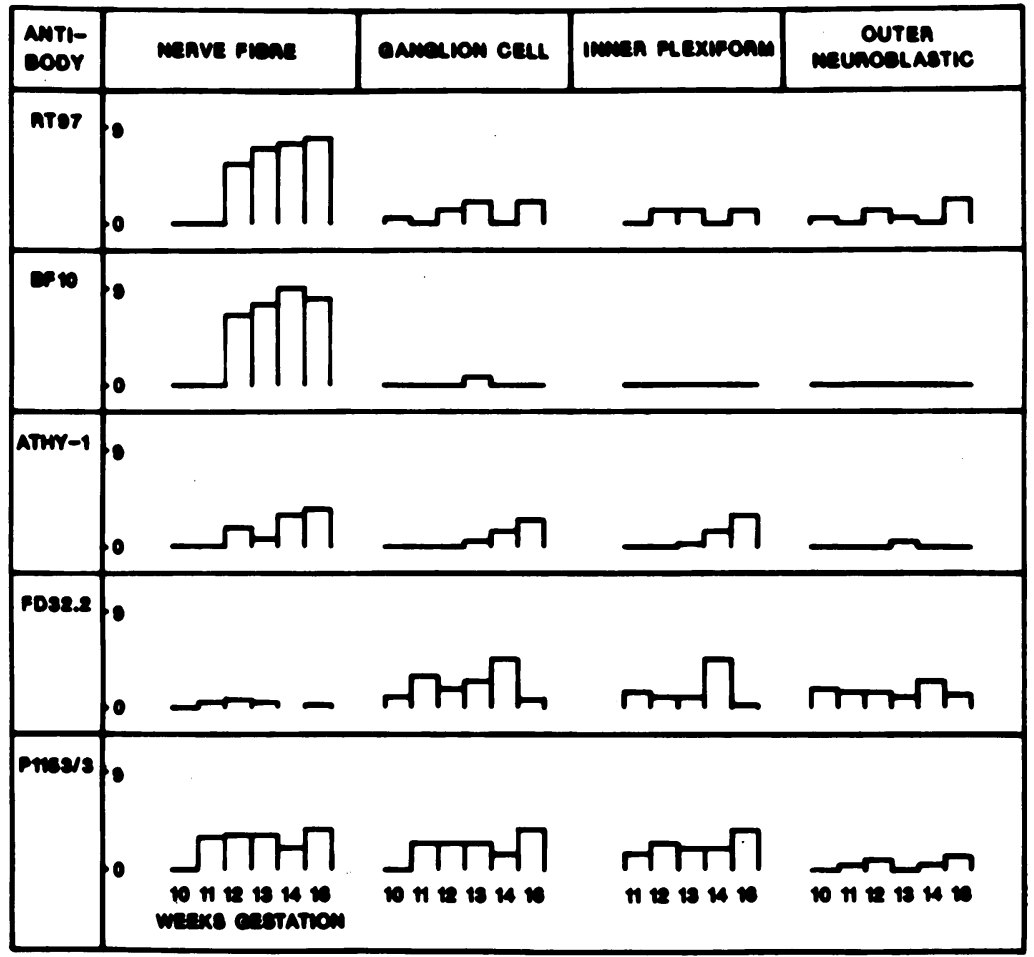

Figure 2: Mean comparative staining intensities of reactions, scored 0 (negative) to 9 (intensely positive), for antibodies showing developmental variation in binding to fetal retinal layers of different ages. Mean values are shown.

THY-1 antigen in the adult inner retinal layers, and to a lesser extent in the inner nuclear and outer plexiform layers. The fetal ganglion cell layers showed an ontogenic increase in antigen expression, from none at 10 and 11 weeks' gestation to mildly positive at 16 weeks. In general those layers derived from the fetal inner

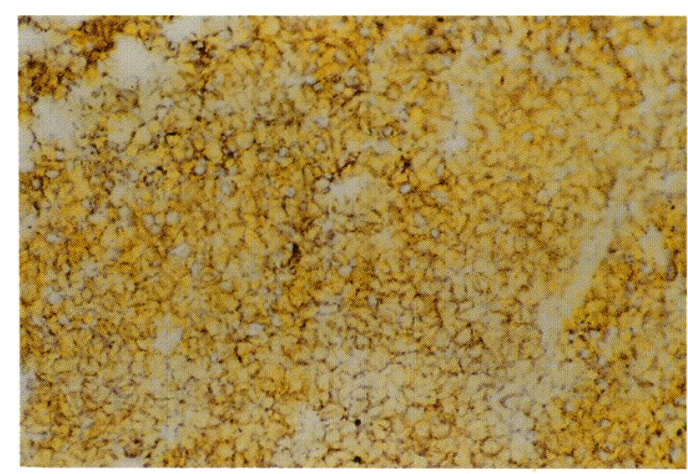

Fig 3A

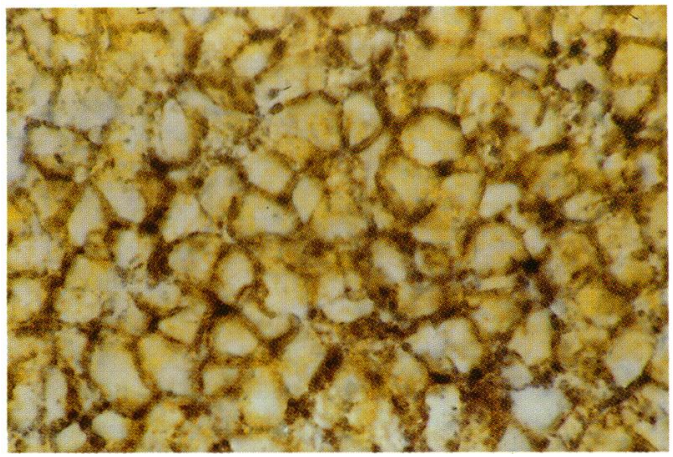

Fig 3B

Figure 3: Retinoblastoma. (A) Sample 2, reaction with Uf 127.11, neuroblastic cell surface marker, scored as 5 . Original magnification $\times 250$. (B) Sample 4 reaction with UF 13 A neuroectodermal cell surface marker, scored as 7. Original magnification $\times 1000$. neuroblastic cell expressed the thy-1 antigen. Retinoblastoma showed a heterogeneous, medium to strong affinity for this antibody.

FD32.2 (human glioma immunogen). Antigen in the adult retina was limited to the photoreceptor layer, and there was a weak to moderate expression throughout fetal retinas of all ages. A marked dissimilarity in the affinity of the adult and fetal choroid/sclera was noted, the adult being substantially more intense. Moderate antigen levels were located in retinoblastoma.

FD44 (human glioma immunogen). The cellular layers of the adult retina displayed a mild affinity for this antibody. There was mild to moderate marking of all fetal layers irrespective of age. A moderate, heterogeneous localisation was observed in retinoblastoma.

P1153/3 (human neuroblastoma immunogen). This antibody was found to locate cell surface antigen only in fetal tissue and retinoblastoma, with no apparent expression in adult retina, showing a degree of oncofetal specificity not found in the other antibodies assessed. Fetal retina showed low to moderate marking, particularly the inner retinal layers. Retinoblastoma displayed mild antigen expression, significantly above control levels.

Uf $13 A, A 2 B 5, H 11$ (neuroectodermal antigens). These cell surface antigens were strongly expressed throughout all retinal and retinoblastoma tissue.

FD19 (glial fibrillary acidic protein antigen). There was mild marking of all the tissues examined, showing little specificity or differential marking of any of the cell types characterised.

M148 (Meduloblastoma antigen). Antigen was expressed throughout all the tissues studied, more so in fetal than in adult ocular tissue, with retinoblastoma displaying an intermediate level of expression.

LE61 (cytokeratin), 2.3F9 (fibronectin), Uf167.11 (fetal brain), MI/N1 (neuroblastoma), Uf308 (fetal brain). These antibodies showed no affinity for antigens present in the tissues examined. Throughout the study they acted as additional negative controls.

In summary, antibodies RT97, UJ181.4, UJ127.11, P1153/3, A Thy-1, FD32.2, FD44, UJ13A, A2B5, H11, FD19, and M148 showed affinity for retinoblastoma; of these the first seven varied in their marking of adult and fetal retinal cell types.

COMPARATIVE IMMUNOHISTOLOGY

The antibody affinities evaluated here are those of RT97, UJ127.11, UJ181.4, BF10, ATHY-1, FD32.2, FD44, and P1153/3, and not those marking antigens which were uniformly distributed.

Adult ganglion cell layer, including the nerve fibre and inner plexiform layers. Tumour associated antigens marked by RT97, UJ127.11, UJ181.4, and ATHY-1 were in the retina predominantly associated with the ganglion cell layers. The BF10 neurofilament antigen was located only in the nerve fibre layer but not in retinoblastoma. FD32.2 and P1153/3 were bound by the tumour and not the ganglion cells. Adult inner nuclear layer. The nuclear layer 
itself showed little correlation in antigen expression with retinoblastoma, and only FD44 and ATHY-1 were found to mark this cell type. When the plexiform layers were also considered there was greater antigenic homology for UJ127.11, UJ181.4, and ATHY-1.

Adult outer nuclear layer. Only FD44 showed any affinity for the inner nuclear cell layer, though the outer plexiform layer bound the retinoblastoma-positive antibodies UJ127.11, UJ181.4, and ATHY-1.

Adult photoreceptor layer. Photoreceptors showed similarity to retinoblastoma in their affinity for RT97, BF10, FD32.2, and FD44, but did not bind the tumour positive antibodies UJ127.11, UJ181.4, and ATHY-1.

Fetal inner neuroblastic layer. This comprises the ganglion cells and their nerve processes. The retinoblastoma-positive antibodies RT97 and ATHY-1, as well as BF10, bound to the inner retina, particularly the nerve fibre layer, after 11 weeks' gestation, and UJ127.11 and UJ181.4 were localised irrespective of developmental stage. The tumour-positive antibodies FD32.2, FD44, and P1153/3 showed greater affinity for

\footnotetext{
Figure 4: Sixteen-week fetal retina. (A) Uf181.4 neuroblastic marker. Nerve fibre layer scored as 9 ganglion cell layer as 3, inner plexiform layer as 3 and outer neuroblastic layer as 0 . Original magnification $\times 100$. (B) A2B5 neuroectodermal marker, scored as 9 throughout retina. Original magnification $\times 250$. (C) $P 1153 / 3$ neuroblastoma marker, scored as 2-3 throughout retina. Original magnification $\times 250 . N F$, nerve fibre layer; $G C$, ganglion cell layer; $I P$, inner plexiform layer; INB, outer neuroblastic layer; $R P E$, retinal pigment epithelium.
}

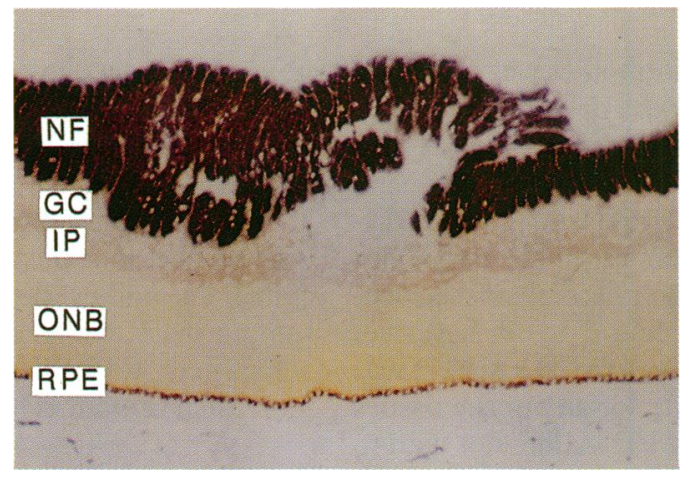

Fig 4A

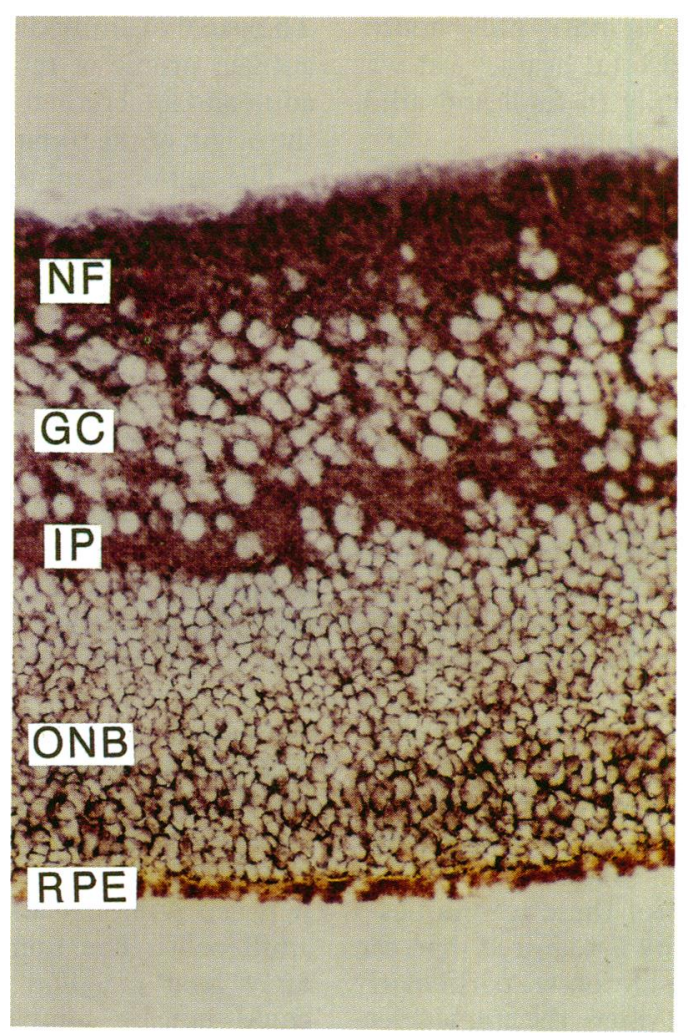

Fig 4B these layers in the fetal retina than in the equivalent adult tissues.

Fetal outer neuroblastic layer. This primordium of the inner and outer nuclear cell layers of later retinas showed significant affinity for only FD32.2 and FD44.

None of the retinal cell types were found to have exactly parallel antigen profiles to retinoblastoma. Adult ganglion and photoreceptor cells each displayed an equivalent degree of homology with the tumour, showing similar affinities for four of the eight significant antibodies. In general those layers derived from the fetal inner neuroblastic layer bound UJ181.4, UJ127.11, and ATHY-1, and those derived from the outer neuroblastic layer were marked by FD32.2 and FD44. All of these antibodies bound to retinoblastoma, with ATHY-1, FD32.2, and FD44 being heterogeneously distributed.

\section{Discussion}

The immunohistological profiles of six retinoblastomas have been documented and compared with those of fetal and adult retinas by means of a panel of 18 monoclonal antibodies recognising antigens associated with a wide range of tissue types.

\section{IMMUNOHISTOLOGY}

This investigation demonstrated little difference in antigen expression between the six retinoblastomas with respect to the 18 monoclonal antibodies used in the panel, though there was marked heterogeneity within individual tumours, possibly representing foci of differentiation, indicating a mixed cell population.

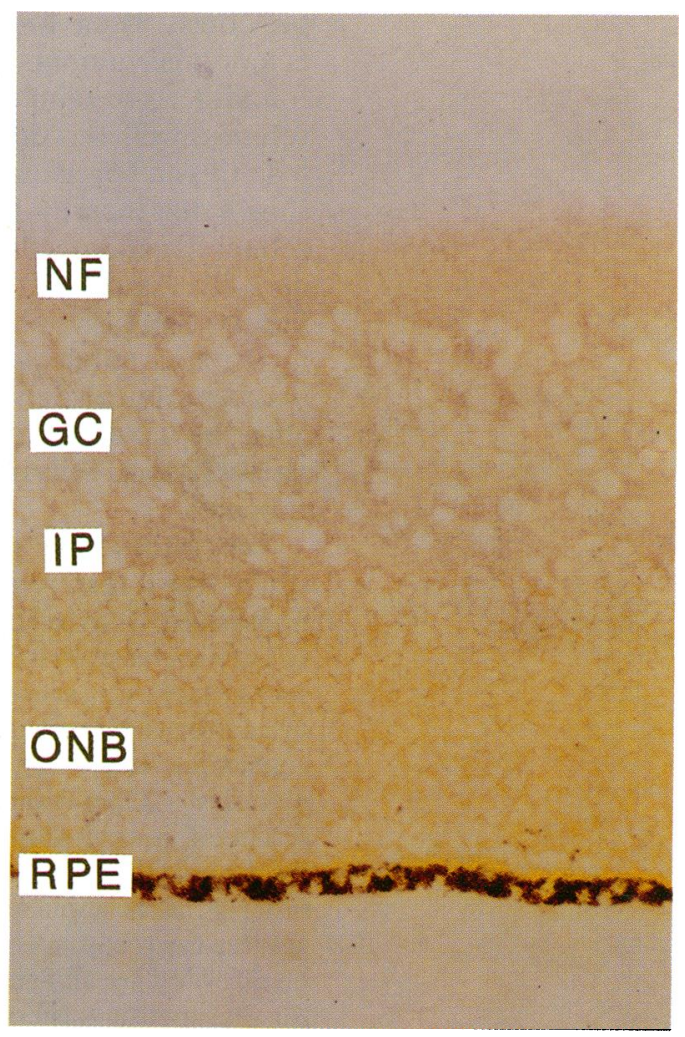

Fig 4C 
Figure 5: Retinal cell development and antigen expression with respect to seven significant antibodies. The tissue staining scored above the overall mean staining of adult retina for the particular antibody is regarded as positive. Antibodies binding to retinoblastoma and adult retinal layers are shown as + , and those marking 13 and 16 week fetal layers are indicated by number.

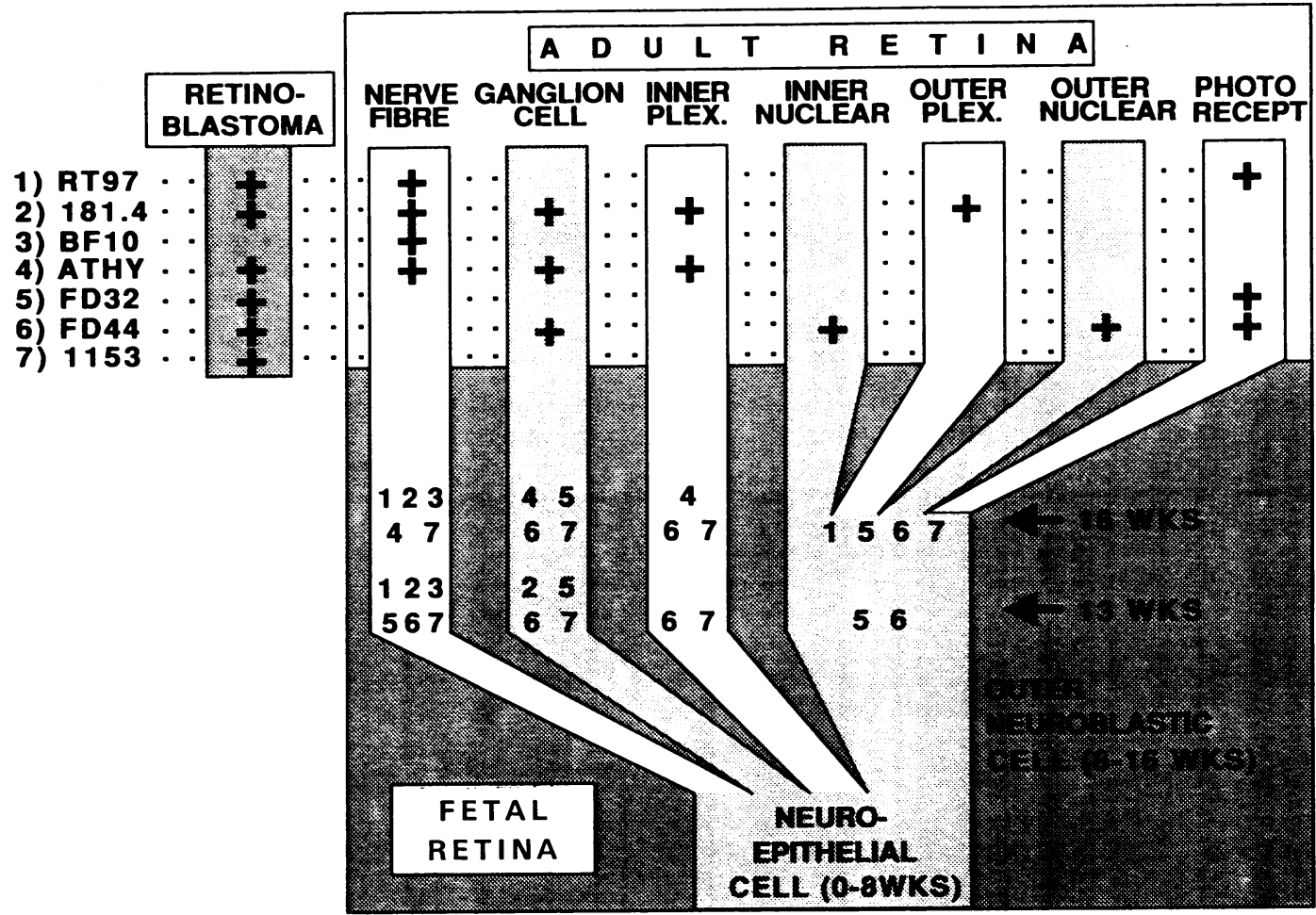

Although none of the antibodies were found to be tumour specific, some did display a degree of oncofetal specificity such as P1153/3 and, to a lesser extent, FD32.2 and FD44. All of the panneurorectodermal and neuroblastic markers displayed strong affinities for retinoblastoma, but UJ167.11 and UJ308, also raised against neuroectodermal tissue, were found to be negative. Moreover the neuroblastoma marker MI/N1 was found to have no reactivity for any of the tissues assessed here. Conversely FD44 does not bind to neuroblastoma in vitro ${ }^{4}$ but was strongly localised to areas of retinoblastoma. UJ181.4 had previously been found to mark only neuroectodermal tumours and fetal brain, ${ }^{+1}$ yet was found here to bind equally to fetal and adult retina as well as retinoblastoma.

In this and previous investigations it has been shown that the Thy-1 antigen is associated with retinal ganglion cells $s^{31}$ and neuroectodermally derived tumours, ${ }^{33.4}$ but also with collagen fibres. ${ }^{32}$ Similarly, FD32.2 displayed affinity for fetal retina, adult photoreceptors, and retinoblastoma, but also choroid and sclera. Thus care must be taken in interpreting the origin of retinoblastoma cells from the expression of these antigens.

The phenotypic profiles identified in this study show that retinoblastomas may be distinguished from related retinal tissue by their antigenic characteristics. Clinical immunolocalisation, however, requires that individual cells be discriminated from their environment by the consistent expression of specific cell surface markers. Operational specificity may be achieved in environments such as cerebrospinal fluid $^{10.22}$ or bone marrow samples. ${ }^{181314}$ For a more general application of these techniques a greater degree of specificity is required than can be afforded by any single antibody, particularly for therapeutic targeting, where the aim is selective tissue destruction. More precise localisa- tions may be achieved by the use of a panel of monoclonal antibodies with overlapping affiniimmunotherapy.

Owing to the heterogeneity of retinoblastoma with respect to some antigens, a panel of monoclonal antibodies best able to characterise a tumour mass, which expresses all potential antigens, may differ from one used to localise individual tumour cells.

\section{HISTOGENESIS}

The panel of antibodies was used to compare the antigen profile of retinoblastoma with those of adult and fetal retinal cells in order to help define

The stem cells of tumours derived from adult tissue have been defined on the basis of residual differentiation characteristics. It is thought that retinoblastoma, arising from immature tissue, as well as retaining existing characteristics may express those within the potential of its stem cell as tumour differentiation occurs $15182023+2$ and hence recapitulate some normal retinal development.

A comparison of the immunohistological characteristics of retinoblastoma and adult retina indicated homology with both ganglion and photoreceptor cells, suggesting that the tumour cells can exhibit characteristics of both these cell types simultaneously or can undergo alternative differentiation under the influence of environmental factors. The antigenic heterogeneity seen in retinoblastoma supports the latter case. The greater oncofetal localisation of P1153/3, FD32.2, and FD44 resulted in a closer homology between retinoblastoma and fetal cells than for adult cells. The homology identified between early fetal ganglion cells and retinoblastoma could not be compared with that of photoreceptor cells, as these cell types are absent at this ties for multiple staining techniques or combined the origin of the tumour. 
stage of development. Despite the parallels in antigen profiles, characteristic differences between retinoblastoma and differentiated retinal layers identified in this and other studies 1517182324 preclude the tumour arising from any particular retinal cell type.

Figure 5 illustrates the retinal cell development ${ }^{43}$ and antigen expression of retinal cells. The closest single comparative cell type with retinoblastoma was found to be the 13-16-week inner retinal cell, though it was found that the tumour expressed antigens associated with both inner and outer retinal layers. Moreover other studies have shown that retinoblastoma exhibits characteristics of photoreceptor differentiation, such as retinal s-antigen, ${ }^{15} 2324$ opsin, ${ }^{15}$ interretinoid binding protein,,$^{15+4}$ neuron-specific enolase, ${ }^{151725}$ and cyclic guanosine monophosphate. ${ }^{15}$ Hence a putative retinoblastoma progenitor cell has potential for photoreceptor as well as inner retinal cell differentiation. In relation to the retinal cell development this implies a tumour origin from a primitive neuroepithelial cell type predominating prior to the 8th week of gestation; more developed cells would not combine the capacity to express both photoreceptor and ganglion cell characteristics. ${ }^{43}$ Such a primitive pluripotential stem cell would be expected to differentiate according to its environment, producing a mixed cell population with the phenotypic heterogeneity found in retinoblastoma, and no exact parallel in antigen expression would be expected with any single mature retinal cell type. The number of such vulnerable neuroepithelial cells is greatest before eight weeks' gestation and would steadily decline throughout later development, resulting in a decreasing incidence of retinoblastoma with increasing age.

This study was funded by the Cancer and Leukaemia in Childhood Trust, the Augustus and Molly Newman Trust, and the National Eye Research Centre. We thank Dr J T Kemshead and Mr H B Coakham for their general assistance and supply of monoclonal antibodies; Mr J Hungerford for providing much of the frozen tumour tissue; and Mr S Bourne for help with the techniques employed in the study.

1 Sikora K, Smedley $\mathrm{H}$, Thorpe P. Tumour imaging and drug targeting. Br Med Bull 1984; 40: 233-9.

2 Jones DH, Goldman A, Gordon I, Pritchard J, Gregory BJ, Kemshead JT. Therapeutic application of radiolabelled monoclonal antibody in nude mice xenografted with human neuroblastoma: tumoricidal effects and distribution studies. Int $\mathcal{F}$ Cancer 1985; 35: 715-20.

3 Allan PM, Garson JA, Harper EI, et al. Biological characterisation and clinical applications of a monoclonal antibody recognising an antigen restricted to neuroectodermal tissues. Int $\mathcal{F}$ Cancer 1983; 31: 591-8.

4 Goldman A, Vivian G, Gordon I, Prichard J, Kemshead JT. Immunolocalisation of neuroblastoma using radio-labelled monoclonal antibody UJ13A. F Pediatr 1984; 105: 252-6.

5 Kemshead JT, Jones DH, Lashford L, et al. 131-I coupled to monoclonal antibodies as therapeutic agents for neuroectodermally derived tumours: fact or fiction. Cancer Drug Deliv 1986; 3: 25-43.

6 Coakham HB, Garson JA, Allan PM, et al. Immunohistological diagnosis of central nervous system tumours using a monoclonal antibody panel. $\mathcal{F}$ Clin Pathol 1985; 38: 165-73.

7 Coakham HB, Garson JA, Brownell B, Allan PM, Harper EI, Kemshead JT. The use of monoclonal antibodies in the immunohistological diagnosis of cerebral and spinal tumours. S Afr $\Im$ Surg 1984; 22: 13-22.

$8 \mathrm{Kemshead} \mathrm{JT,} \mathrm{Coakham} \mathrm{HB.} \mathrm{The} \mathrm{use} \mathrm{of} \mathrm{monoclonal} \mathrm{anti-}$ bodies for the diagnosis of intracranial malignancies and small round cell tumours of childhood. F Pathol 1983; 141: 249-57.

9 Bullard DE, Bigner DD. Applications of monoclonal antibodies in the diagnosis and treatment of primary brain tumors. F Neurosurg 1985; 63: 2-16.

10 Coakham HB, Garson JA, Brownell B, Kemshead JT. Monoclonal antibodies as reagents for brain tumour diagnosis: a review. F $R$ Soc Med 1984; 77: 780-7.

11 Darbyshire PJ, Bourne SP, Allan PM, et al. The use of a panel of monoclonal antibodies in pediatric oncology. Cancer 1987; 59: 726-30.
12 Coakham HB. Garson JA, Brownell B, et al. Use of monoclonal antibody panel to identify malignant cells in cerebrospinal fluid. Lancet 1984; i: 1095-7.

13 Jonak ZL, Kennet RH, Bechtol KB. Detection of neuroblastoma cells in human bone marrow using a combination of monoclonal antibodies. Hybridoma 1982;1: 349-68.

14 Kemshaed JT, Goldman A, Fritschy J, Malpas JS, Pritchard $J$. Use of panels of monoclonal antibodies in the differentia diagnosis of neuroblastoma and lymphoblastic disorders. Lancet 1983; i: $12-4$.

15 Rodrigues MM, Wiggert B, Shields J, et al. Retinoblastoma: immunohistochemistry and cell differentiation. Ophthalmology 1987; $94: 378-87$.

16 Char DH, Wood IS, Huhta K, Rand N, Morita CT, Howes EL. Retinoblastoma: tissue culture lines and monoclonal antibody studies. Invest Ophthalmol Vis $S$ ci 1984; 25: 30-40.

17 Messmer EP, Font RL, Kirkpatrick JB, Hopping W. Immunohistochemical demonstration of neuronal and astrocytic differentiation in retinoblastoma. Ophthalmology 1985; 92: 167-73.

18 Tsokos M, Kyritsis AP, Chader GJ, Triche TJ. Differentiation of human retinoblastoma in vitro into cell types with characteristics observed in embryonal or mature retina. Am F Pathol 1986; 123: 542-52.

19 Jiang Q, Lim R, Blodi FC. Dual properties of cultured retinoblastoma cells: immunohistochemical characterisation of neuronal and glial markers. Exp Eye Res 1984; 39: 207 15.

20 Kyritsis AP, Tsokos M, Triche TJ, Chader GS. Retinoblastoma - origin from a primative neuroectodermal cell? Nature 1984; 307: 471-3.

21 Terenghi G, Polak JM, Ballesta J, et al. Immunocytochemistry of neuronal and glial markers in retinoblastoma. Virchows $\operatorname{Arch}(A) 1984 ; 404: 61-73$.

22 Lane JC, Klintworth GK. A study of astrocytes in retinoblastomas using the immunoperoxidase technique and antibodies to glial fibrillary acidic protein. Am $\mathcal{F}$ Ophthalmol 1983; 95: 197-207.

23 Mirshahi M, Boucheix C, Dhermi P, Faure JP. Expression of the photoreceptor-specific $S$-antigen in human retinoblastoma. Cancer 1986; 57: 1497-500.

24 Donoso LA, Folberg R, Arbizo V. Retinal S-antigen and retinoblastoma. Arch Ophthalmol 1985; 103: 855-7.

25 Molnar ML, Stefansson K, Marton LS, Tripathi RS, Molner GK. Immunohistochemistry of retinoblastomas in humans. Am F Ophthalmol 1984; 97: 301-7.

26 Kohler G, Milstein C. Continuous cultures of fused cells secreting antibody of predefined specificity. Nature 1975 256: 495-7.

27 Kemshead JT, Bicknell D, Greaves MF. A monoclonal antibody detecting an antigen shared by neural and granulocytic cells. Pediatr Res 1981; 15: 1282-6.

28 Anderton BA, Breinburg D, Downes MJ, et al. Monoclonal antibodies show that neurofibrillary tangles and neurofilaments share antigenic determinants. Nature 1982;298: 84-6.

29 Garson JA. The development and characterisation of monoclonal antibodies for use in neuropathology. MD thesis. University of Birmingham, 1983.

30 Kemshead JT, Fritschy J, Garson JA, et al. Monoclonal antibody UJ127.11 detects a 220,000-240,000 Kdal glycoprotein present on a sub set of neuroectodermally derived cells. Int F Cancer 1983; 31: 187-95.

31 Barnstable CJ, Drager UC. THY-1 antigen: a ganglion cell specific marker in rodent retina. Neuroscience $1984 ; 11$ : 84755.

32 Morris RJ, Ritter MA. Association of THY-1 cell surface differentiation antigen with certain connective tissues. Cell Tissue Res 1980; 206: 459-75.

33 Seeger RC, Danon YK, Rayner SA, Hoover F. Definition of a Thy-1 determinant on human neuroblastoma, glioma, sarcoma and teratoma cells with a monoclonal antibody. f Immunol 1982; 128: 983-9.

34 Kemshead JT, Ritter MA, Cotmore SF, Greaves MF. Human Thy-1: expression on the cell surface of neuronal and glial cells. Brain Res 1982; 236: 451-61

35 Kennett RH, Gilbert F. Hybrid myelomas producing antibodies against a human neuroblastoma antigen present on fetal brain. Science 1979; 203: 1120-1.

36 Eisenbarth GS, Walsh FS, Nirenberg N. Monoclonal antibody to a plasma membrane antigen of neurones. Proc Natl Acad Sci USA 1979; 76: 4913-7.

37 Kemshead JT, Walsh F, Pritchard J, Greaves M. Monoclonal antibody to gangliocide GQ discriminates between haemopoietic cells and infiltrating neuroblastoma tumor cells in bone marrow. Int $f$ Cancer 1981; 27: 447-52.

38 Walsh FS, Moore SE. Expression of muscle cell surface antigen $5.1 \mathrm{H11}$ in infantile or juvenile spinal muscular atrophy. Neurology 1986; 36: 1140-2.

39 Lane EB. Monoclonal antibodies provide specific intramolecular markers for the study of epithelial tonofilament organisation. F Cell Biol 1982; 92: 665-73.

40 Kemshead JT, Bicknell D, Greaves MF. A monoclonal antibody detecting an antigen shared by neural and granulocytic cells. Pediatr Res 1981; 15: 1282-6.

41 Helson C, Helson L. Ocular tumors react with antineuroblastoma monoclonal antibodies. Invest Ophthalmol Vis Sci 983; $24: 1150-2$.

42 Kivela T, Tarkkanen A. Intermediate filaments in the retina and retinoblastoma. BrMed F 1985; 290: 285 .

43 Sigelman J, Ozanics V. Retina. In: Jackobiec FA, ed. Ocula anatomy, embryology and teratology. Philadelphia: Harper and Row, 1982: 441-506.

44 Fong SL, Balakier H, Canton M, Bridges CDB, Gallie B. Retinoid binding proteins in retinoblastoma tumors. Cancer Res 1988; 48: 1124-8. 